\title{
EXPERIENCIAS DE CORDILLERA, ECOS DE FRÍO: RELATOS CRUZADOS ENTRE CHILE Y QUITO EN EL SIGLO XVI ${ }^{1}$
}

\author{
Alejandra Vega \\ Universidad de Chile \\ avega.cecla@gmail.com
}

\section{RESUMEN / ABSTRACT}

La narración de la secuencia de la conquista del Perú nos enfrenta con la fijación de dos episodios diferentes aunque articulados: la jornada a Quito de Pedro de Alvarado en 1534 y la expedición a Chile de Diego de Almagro, entre 1535 y 1536, que incluyen, ambas, una travesía cordillerana. El presente artículo discute los ecos que pueden rastrearse de los relatos acerca de estas expediciones en un conjunto de obras redactadas en torno a 1550 (Gonzalo Fernández de Oviedo, Francisco López de Gómara, Pedro Cieza de León y Agustín de Zárate). A partir de convergencias y diferencias inesperadas en estos textos, se discute la importancia de la circulación oral de historias entre los conquistadores del Perú. Se plantea que la práctica social de la conversación oral permitió fijar, además de estas historias, una temprana conceptualización cristiana de los límites del Tawantinsuyu. En ella se concibió a Quito y Chile como las marcas fronterizas del espacio recién conquistado, permitiendo que ambos territorios se superpusieran al caracterizarse a partir a un mismo conjunto de imágenes sobre la experiencia de la cordillera.

Palabras ClaVE: memoria oral, Andes, cultura de conquista, siglo XVI.

${ }^{1}$ Este artículo tiene una doble adscripción. Por una parte, tiene su origen en las reflexiones que se plasmaron en mi tesis de Doctorado, Descripción geográfica e identidad territorial: representaciones hispanas de la cordillera de los Andes del reino de Chile en el siglo XVI (Pontificia Universidad Católica de Chile, 2005) que, tal como el título lo indica, se concentró en las narrativas sobre el espacio cordillerano de Chile. Esta visión fue ampliada al contrastarse con las narrativas acerca del territorio del virreinato del Perú y el estudio de las prácticas de conocimiento en relación con el territorio en el periodo, cuyo análisis se aborda en el marco del Proyecto FONDECYT n ${ }^{\circ} 1070938$. 
In the Hispanic narrative of the conquest of Peru, we can identify two different yet related episodes: Pedro de Alvarado's journey to Quito in 1534 and the expedition to Chile commanded by Diego de Almagro in 1535-1536. This article discusses the echoes than can be pinpointed in the accounts of both experiences in a corpus of texts written or printed around 1550 (Gonzalo Fernández de Oviedo, Francisco López de Gómara, Pedro Cieza de León and Agustín de Zárate). By tracing unexpected similarities and differences, this proposal discusses the importance of oral circulation of histories amongst Peruvian conquistadors. The features of conversation, as a social practice, allowed the register of an early Christian conceptualization of the Tawantinsuyu territory. Here Quito and Chile became frontier marks of the conquered space, thus enabling a superposition of these places as they were characterized by a shared set of mountain-related images.

KEY WORDS: oral memory, Andes, culture of conquest, Sixteenth Century.

La narración hispana de la conquista del Perú da cuenta de dos episodios que, siendo diferentes, están relacionados. En 1534, una hueste al mando del gobernador de Guatemala, Pedro de Alvarado, desembarca en las costas de la mar del Sur y se interna hacia las alturas andinas de Quito, amparado en una capitulación otorgada por la Corona. Al año siguiente, el capitán Diego de Almagro parte desde el Cuzco hacia el Estrecho a fin de tomar posesión de la gobernación que le había sido concedida, cruzando los Andes en 1536, para desembocar en el valle de Copiapó.

Estas expediciones pueden vincularse en razón de varios elementos contextuales. En primer lugar, se despliegan próximas en el tiempo y parecen ser el resultado directo de la circulación de noticias acerca del legendario reparto de Cajamarca y el consiguiente deseo de participar en los beneficios de la conquista del Perú. No obstante, se trata de expediciones "fracasadas" en el sentido de que ninguna logra consolidar posiciones territoriales de dominio, en el marco de la extensión del poder hispano por el continente. Hay, además, relaciones explícitas entre los actores involucrados en ambos episodios. Primero, pues Almagro desempeña una función crucial en la contención del impulso conquistador de Alvarado hacia el territorio de lo que se considera jurisdicción de Francisco Pizarro. Pero más importante aún, fruto de las negociaciones entre ambos capitanes, una parte de la hueste de Alvarado permanece en el Perú cuando éste se retira y sigue a Almagro cuando se inicia la conquista de Chile. Por último, ambas expediciones enfrentan una travesía cordillerana.

A partir de estas confluencias, el presente artículo propone una lectura comparada de algunos relatos en que se da cuenta de estos acontecimientos. En 
particular, remito a un conjunto de crónicas e historias, escritas y/o publicadas en las décadas de 1540 y 1550 en las que se narran ambos episodios: la Historia general y natural de las Indias de Gonzalo Fernández de Oviedo; la Historia general de las Indias de Francisco López de Gómara; la Crónica del Perú de Pedro Cieza de León; y la Historia del Descubrimiento y Conquista del Perú de Agustín de Zárate.

Se trata, a todas luces, de un corpus heterogéneo: Zárate y Cieza estuvieron en el Perú en la década de 1540, mientras que Fernández de Oviedo no conoció la América meridional y López de Gómara nunca estuvo en las Indias. Por otra parte, los textos de Zárate y Gómara fueron impresos, traducidos y reimpresos reiteradamente en el siglo XVI, mientras que las crónicas de Oviedo y Cieza solo se publicaron parcialmente, quedando inéditos hasta el siglo XIX la mayor parte de sus escritos, incluidas las secciones relativas a los acontecimientos a los que propongo prestar atención.

Estos textos comparten, sin embargo, rasgos que quisiera destacar. En primer lugar, y tal como lo sugieren los títulos que llevan las obras mencionadas, se trata de crónicas e historias, vocablos empleados en este contexto como sinónimos para referir a la narración, con estructura temporal, de hechos dignos de memoria (Mignolo, Cartas 75-76; Stoll 154). Al menos dos elementos centrales se desprenden de esta constatación. Por una parte, resuena en ellos una narración mayor en la cual se inscriben los episodios que nos ocupan: el de la conquista del Perú, en el caso de Zárate y Cieza; el de la expansión del imperio hispano, en el caso de Oviedo y Gómara. Con sus diferencias, ambas secuencias se entienden como el relato de la extensión del cristianismo y sus agentes por el orbe. De modo que se conciben como expresión de una misma matriz teleológica que expresa, ya sea el despliegue imperial y/o la difusión del proceso civilizatorio y evangelizador que sostienen el proyecto colonial.

En segundo lugar, aunque estas obras se inscriben en géneros ya conocidos en Europa, responden a la necesidad de dar cuenta de una situación histórica única, así como a condiciones de escritura que contradicen algunos principios fundamentales de la prescriptiva historiográfica humanista. Esta tradición establecía el carácter ejemplar de la historia, su calidad de magistra vitae, cuyo ejercicio suponía una vasta preparación formal, la máxima serenidad e independencia para depurar y estructurar un argumento, el que, a su vez, debía ser vertido en una narración sometida a las reglas de la retórica. En tensión con este modelo, quienes acometen la escritura de las historias de América no siempre tienen la preparación formal requerida, y vinculan la utilidad de la historia, no tanto con su condición ejemplificadora, sino con la 
posibilidad de fijar y comunicar todas las cosas de las Indias, aun a riesgo de contravenir las reglas de la buena presentación (Stoll 146-148).

Por otra parte, al abarcar un tramo temporal y geográfico más amplio que el de la propia vivencia, quienes escriben estos relatos deben recurrir tanto a "su propia experiencia como a fuentes y documentos diversos" (Stoll 155). En este marco, la repetición del tópico de narrar lo visto con los propios ojos como fuente de legitimación del autor y de autenticidad de lo registrado (Invernizzi 28), se amplía para dar cabida a numerosos episodios de los cuales no se tiene conocimiento de primera mano. De hecho, los acontecimientos que queremos analizar acá caen todos bajo este común denominador. Ubicados a mayor o menor proximidad del escenario geográfico al cual remiten, los textos que nos interesan se escribieron entre dos y tres lustros después de los acontecimientos que involucran a Alvarado y Almagro, echando mano a los relatos que circulaban en diversos contextos de la sociedad colonial en formación y que involucraban, entre otros, al grupo reconocido como "los primeros conquistadores", a los soldados desplazados del reparto de bienes materiales y simbólicos fruto de la conquista, a aquellos llamados a integrarse a la institucionalidad virreinal y también a los diversos grupos metropolitanos vinculados, de variadas maneras, a la empresa de las Indias. Siguiendo a Antonio Cornejo Polar, me interesa recordar que la producción de imágenes sobre el mundo es el resultado "de extensas y sutiles semiosis, en las que el tejido de los signos va construyendo figuraciones más o menos fluidas y a veces contrapuestas entre sí. Estas imágenes funcionan sincrónicamente, coexistiendo varias a la vez, cada una de ellas supone además una conciencia específica del tiempo que les corresponde como historia" (Cornejo Polar, Invención 140). Acá resultan claves los conceptos de fluidez, contraposición, sincronía, contexto como abordajes de una cultura, en este caso, la del periodo de la conquista, que se revela como compleja, cambiante y contradictoria.

El reconocimiento de este conjunto de condiciones resulta fundamental para la presente propuesta de lectura. Por una parte, los relatos parciales a los que aludiremos no son fragmentos aislados, sino que se inscriben en un horizonte común que los contiene, lo que nos permite acercarlos y contrastarlos. Al mismo tiempo, dado que éstos no constituyen una narrativa unívoca del periodo y sus acontecimientos, podemos indagar en los ecos discernibles entre relatos diferentes, y preguntarnos por sus disonancias. En particular, proponemos un acercamiento a este tema desde la pregunta por las mediaciones entre el registro escrito y la circulación oral de noticias en un periodo en que se fijan las historias de la conquista. Más que reconocer 
racionalidades fuertemente diferenciadas, me interesa destacar que hay entre las esferas de lo escrito y lo oral "una ancha y complicada franja de interacciones" (Cornejo Polar, Escribir 19).

\section{ALVARADO EN LA CORDILLERA}

Presentaremos en primer lugar las narraciones de la malograda expedición de Pedro de Alvarado. Amparado en una capitulación de 1532, el adelantado Alvarado desembarcó con una hueste de quinientos españoles y cuatro mil indios procedentes de Nicaragua y Guatemala a la altura de la bahía de Caráquez (actual costa de Ecuador). Desde allí, inició su ascenso hacia las tierras de Quito cruzando hasta los valles interandinos por uno de los pasos más difíciles, entre el Chimborazo y el Carihuairazo (Gómez Pérez y Marchena 31). Al relatar este avance, los textos analizados remiten a un conjunto limitado de elementos para dar cuenta de la marcha y caracterizar el territorio recorrido: el desembarco en la costa, lo montuoso del camino, el hambre y la sed padecidas por la hueste, la ceniza volcánica que cae del cielo, y las dificultades del paso cordillerano.

Estos elementos están presentes en la tercera parte la Historia general y natural de las Indias escrita por Gonzalo Fernández de Oviedo entre 1535 y 1557, y que permaneció inédita hasta su publicación, por la Real Academia de la Historia, a mediados del siglo XIX (O'Gorman 63). La llamada jornada a Quito de Alvarado se inserta en el relato de la conquista del Perú, donde Oviedo señala:

Quando don Pedro de Alvarado entró por allí la vía de Quito, halló tanta falta de agua, que peresciera su gente si no hallaran unos cañaverales de las cañas gordas de Castilla de Oro, que cortándolas, las hallaron llenas de agua, de que bebieron las gentes é los caballos. Cerca desta tierra le llovió al dicho Alvarado dos días tierra bermeja, lo cual ovieron por mal pronóstico; e tal le subcedió, porque al pasar un puerto de nieve adelante, le quedaron helados más de septenta u ochenta hombres e mujeres, entre indios y españoles (tomo IV, 221-222).

En la secuencia de la narración aparece primero la sed asociada a una tierra de la cual no se informa otra cosa y, luego, cenizas como anticipo del escenario andino que se despliega a continuación: un espacio caracterizado apenas como puerto de nieve. Respecto de éste, Oviedo ya había señalado 
en el Libro Primero "que tracta de la geographia" de la tercera parte de su Historia, que bajo la línea equinoccial, "hay muchas sierras y montes con perpetua nieve, á causa de su altura, pues que encumbrándose háçia el çielo, passan la region del fuego é penetran á caliginoso ayre, para cubrirse de nieve é aver grandíssimo frío é hielos allá arriba" (1-2). La imagen así configurada vincula altura, oscuridad y un frío superlativo capaz de dejar helados a hombres y mujeres.

Al informar el ascenso al espacio cordillerano, el conjunto de obras cuya lectura aquí presento recoge y reitera como elementos centrales del relato la nieve y los cuerpos congelados. Es el caso de la Istoria general de las Indias y conquista de México de Francisco López de Gómara, impresa en Zaragoza en 1552. Se trata de una historia elaborada en base a testimonios indirectos, incluidos los manuscritos de la Historia de Fernández de Oviedo (O'Gorman 50), pues Gómara no vino nunca al Perú ni a América. Sin embargo, debido a las numerosas ediciones tempranas, fue uno de los autores determinantes en "la fijación de una imagen histórica de los tiempos españoles iniciales" (Pease, Crónicas 29). Respecto de la experiencia cordillerana de Alvarado, dice Gómara:

Pasaron también unas sierras muy nevadas, y se maravillaron de lo mucho que nevaba tan por debajo de la Equinoccial. Se helaron allí sesenta personas, y cuando se vieron fuera de aquellas nieves, daban gracias a Dios, que de ellas los habían librado, y daban al diablo la tierra y el oro, puesto que iban hambrientos y muriéndose (186-187).

Como puede verse, Gómara recupera la visión corográfica de la esfera terrestre dividida horizontalmente por influjo del astro solar, que se expresa asimismo en el escrito de Oviedo $^{2}$; inscribiendo, al mismo tiempo, la particularidad de esta tierra en el repertorio de la maravilla americana. En este contexto, se provee una descripción más detallada de la geografía, al caracterizar el espacio recorrido como sierras, donde nieva mucho.

Al mismo tiempo, se da cuenta de elementos que permiten identificar la tensión entre lo que Beatriz Pastor denomina discurso del trabajo, es decir, la amplificación del sufrimiento como sustento de la loa a la labor realizada por

2 Siguiendo a Curry, denominamos relato corográfico a aquel que, inspirado en la teoría de los climas, identifica características propias a la tierra, los habitantes, la flora y fauna de las zonas templadas, tórridas y gélidas, respectivamente (504-505). 
los conquistadores y el discurso del fracaso: una transformación del modelo épico del relato de la conquista en pos de la lucha por la supervivencia contra una naturaleza en exceso hostil (Pastor 265-293).

A diferencia de los dos cronistas anteriores, Agustín de Zárate sí estuvo en el Perú. Llegado como contador por efecto de un nombramiento real en 1543, regresó a España en 1545, donde acometió la redacción de su Historia del Descubrimiento y Conquista del Perú, a partir de los memoriales y diarios que pudo reunir durante su estancia americana. $\mathrm{Su}$ historia fue publicada en Amberes a instancias del príncipe Felipe en 1555 (Esteve Barba 464-465). Las sucesivas reimpresiones y traducciones de esta obra revelan la popularidad de la que gozó en el siglo XVI, y la gran influencia que ejerció entre sus contemporáneos (Pease, Introducción XI, LI y LVIII).

El pasaje relativo a la travesía cordillerana de Pedro de Alvarado contenido en la Historia de Zárate señala:

Y después de auer pasado tan trabajoso camino, que lo más dél fueron abriendo a mano con hachas y machetes, topó delante sí vna cordillera de sierras neuadas, donde de continuo neuaua y hazía muy gran frío, y la hora que le pareció más conueniente determinó passar por portezuelo que allí auía, donde se le quedaron elados más de sesenta hombres, aunque todos para passar se vistieron todas quantas ropas trayan, y yuan corriendo sin esperar ni socorrerse los vnos a los otros. Donde aconteció que lleuando un español consigo a su muger y dos hijas pequeñas, viendo que la muger e hijas se sentaron de cansadas y que él no las podía socorrer ni lleuar, se quedó con ellas, de manera que todos quatro se elaron; y aunque él se pudiera saluar, quiso más perecer allí con ellas. Y con este trabajo y peligro passaron aquella sierra, teniendo a gran buenauentura auer podido verse de la otra parte $(90)$.

Aquí también, entonces, se configura un espacio geográfico de sierras muy nevadas, donde se quedan helados los hombres: hombres que corren para salvarse, portezuelo donde nadie quiere socorrer al prójimo, salvo un español que se detuvo y quedó helado, sentado junto a su mujer e hijas. Fruto de estas historias insertas en la trama del relato, se fija con mayor claridad el discurso desmitificador del fracaso, en que el buen cristiano perece y solo se salva aquel que ha renunciado a los valores civilizatorios que guían la empresa de conquista. 
El relato de Pedro Cieza de León es el más extenso y profuso en detalles sobre la travesía cordillerana. Cieza también estuvo en el Perú en la década de 1540, en particular entre 1548 y 1550, iniciando entonces la redacción de su monumental Crónica del Perú. Durante la vida de Cieza, solo alcanzó a ver la luz la primera parte de esta obra, impresa en Sevilla en 1553 y consagrada a la descripción geográfica del virreinato. La tercera parte -donde se relata la conquista hispana sobre los Inka, y se da cuenta de las expediciones de Alvarado y Almagro- permaneció inédita hasta el siglo XIX (Pease, Crónicas 25).

La narración que ofrece Cieza de León de la jornada de Alvarado a Quito no constituye una secuencia unitaria. La razón que esgrime el propio Cieza es que "por ninguna manera puedo proseguir una materia hasta el cavo porque en un mismo tiempo pasavan todas las cosas que voy contando" (tercera parte 216), de modo que sus diferentes etapas se van entretejiendo en el relato de la gesta conquistadora de Pizarro: desembarco, pantanos y tierras enfermas, sed y hambre en montañas oscuras, malos tratos, padecimientos y grandes pérdidas en vidas humanas.

En este relato se intercalan noticias que prefiguran y anuncian los trabajos sin igual que la expedición enfrentará en las sierras nevadas: la astucia de un platero que reconoció el valor de las esmeraldas de Xipijapa, reuniendo disimuladamente gran cantidad de piedras "para con ellas volverse en España"; promesa de riqueza que, junto al platero, quedaron heladas "en las nieves y fríos de adelante" (217); o el canibalismo de los indios de Guatemala, que "comieron infinidad de jente de los naturales destos pueblos, $[\ldots]$ y despues fueron los más dellos elados de frío" en castigo divino por sus "detestables pecados" (218).

Precedidos de una sucesión de infortunios y trabajos, la expedición a Quito se enfrenta finalmente con las sierras nevadas. Temor, determinación e invocaciones a Dios marcan el inicio de la travesía. En razón de la extensión del relato de este episodio, propongo a discusión solo algunos pasajes, que me parecen particularmente relevantes:

El viento hera tan rezio que los penetrava y hazía perder el sentido. No tenían abrigo y era el frío tan grande que cayan faltos de toda virtud, boqueando echavan las ánimas de los cuerpos. Muchos ovo que, de cançados, se arrimavan [a] algunas de las rocas e peñascos que por entre las nieves avía; quan presto como se ponían, se quedavan elados y sin ánimas, de tal manera que parecían espantajos [...].

No se valían los unos a los otros ni se abaxaban a levantar al que caya, aunque fuera hijo ni hermano [...] Otro español que venía en 
el canpo, muy robusto, yendo en una yegua, apeándose para apretar la sincha que venía floxa, no puso bien los pies en el suelo quando él y ella feneçieron (248-9).

Aquí, el helarse de los cuerpos adopta formas bien precisas: boqueando, se echa el ánima afuera, que es viento, como el viento que sopla recio; los cuerpos sin vida quedan arrimados a las peñas, transformados en simulacros de vida, como el espantajo ${ }^{3}$ o como ese español, helado en el acto de apretar la cincha de su montura. La transformación del cristiano en simulacro, cristalizada en la pérdida del ánima se vincula con el abandono, por efecto del frío extremo, de la fortaleza, la prudencia, la justicia y la temperancia, que constituyen la virtud o hábito del ánimo bien instruido 4 .

Quisiera destacar el hecho de que, pese a las significativas variaciones en la extensión, las cuatro obras analizadas presentan un vocabulario y unos motivos que se repiten una y otra vez para dar cuenta de la travesía cordillerana de Alvarado. Más significativo aún me resulta constatar que esta reiteración se extiende a la narración del cruce de la cordillera por la hueste de Almagro en su camino a Chile.

\section{ALMAGRO EN LA CORDILLERA}

Cerca de un año después de negociar con Alvarado su retiro del Perú, Diego de Almagro partió del Cuzco hacia el Estrecho a la cabeza de una expedición destinada a tomar posesión de las tierras que le habían sido concedidas por el monarca mediante una capitulación otorgada en 1534 (De Ramón 14). Luego de atravesar el altiplano y recorrer parte del territorio que hoy constituye el noroeste argentino, Almagro y su hueste se enfrentaron al espacio cordillerano y cruzaron hasta el valle de Copayapo por el paso de San Francisco.

En el relato de la travesía cordillerana de Almagro se introduce una modulación significativa respecto de las narraciones de la experiencia de

3 "Espantajo. El trapo ú figura de trapos que se suele poner en los arboles para espantar los páxaros à fin que no piquen la fruta ni las plantas menudas" (Diccionario de Autoridades 591).

${ }^{4}$ En el Vocabulario de Alonso de Palencia impreso en 1490 se consigna la siguiente entrada para Virtud: "Virtud es habito del animo bien instituydo sus especies son la fortaleza, la prudencia, la justicia, la temperancia; llamase virtus porque proseuerando en sus fuerças no se vençe de las ajenas" (Tomo II, fol. CCCCXXX). 
la hueste de Alvarado que hemos presentado hasta ahora, al identificarse el paso de las sierras como oleadas o cruces sucesivos. Como consecuencia de lo anterior, quienes se internan después en la cordillera se ven enfrentados a los despojos de quienes los precedieron.

El relato de la experiencia cordillerana de Almagro escrito por Gonzalo Fernández de Oviedo se divide así entre la travesía de Almagro y la que realiza, varios meses después, su capitán Juan de Herrada, quien traía refuerzos para la expedición. El "frío é demasiados vientos que de continuo allí se recrean" (Fernández de Oviedo 266) denotan aquí también el espacio cordillerano, donde los trabajos padecidos conllevan una degradación de la figura del conquistador:

En el dar é socorrer de comida no se valía el hijo al padre, ni se ayudaban los hermanos en la resistencia del frío, ni había abrigo, ni amigo que conosciese á otro, é de si mesmos andaban escandalizados, esperando de sus personas lo mesmo que la muerte había fecho con sus esclavos é indios que los servían, é asi se les representaba a cada paso (Fernández de Oviedo 266).

Tal como en la narración de Zárate y Cieza que ya presentamos, esta degradación conlleva una ruptura de los vínculos básicos: ante la adversidad no se auxilia al prójimo, ni siquiera entre hijos, padres y hermanos. En el relato de Oviedo, la excepción la constituye el propio Almagro, quien "nunca dejó de llamar á Dios en su socorro é de encomendar á si é á todos en su misericordia" (Fernández de Oviedo 266).

Algunos párrafos más adelante, Oviedo relata el cruce de Juan de Herrada por el mismo paso cordillerano, señalando lo siguiente:

E porque para siempre quede desto memoria, no se debe dejar de escribir que en diez jornadas del puerto comían los españoles por fiesta muy señalada los caballos que había cinco messes que se les habían muerto á los que primero pasaron con el Adelantado, los cuales estaban conservados, no como carne momia, sino frescos é sin hedor, por el demasiado viento é frío é sequedad de la tierra [...] padescian el frío que aquestos nuestros españoles, donde es dicho pasaron, para defensa é reparo del cual, de cuerpos de hombres muertos hicieron paredes para detras dellas abrigarse (277-278).

Los cuerpos congelados sirven entonces de alimento: los de los caballos, a los españoles, nos dice Oviedo; los de los indios muertos, a los propios 
indios, dirá Cieza a continuación. Estos mismos cuerpos sirven asimismo de cobija, casa o defensa.

En la Historia de Zárate, el recorrido por este infierno gélido poblado de cuerpos helados se atribuye, ya no a los refuerzos que llegaron tras Almagro a Chile, sino al propio Almagro, en una recreación ficcionada de su regreso al Perú por el mismo camino que lo había llevado hasta Chile ${ }^{5}$ :

$\mathrm{Y}$ era tan grande la frialdad de la tierra que quando dende en cinco meses don Diego boluió al Cuzco halló en muchas partes algunos de los que murieron a la yda en pie, arrimados a alguna peña, elados con los cauallos de rienda; tan bien elados y tan frescos y sin corrupción como si entonces acabaran de morir (103).

Sobre este punto, es altamente coincidente la narración de López de Gómara que presentamos a continuación:

Tuvo Almagro muchos trabajos a la vuelta; comió los caballos que se murieron a la ida, cosa bien de notar, porque al cabo de cuatro meses o más tiempo estaban por corromper, y tan frescos, según dicen, como recién muertos. Estábanse también los españoles arrimados a las peñas con las riendas en las manos, que parecían vivos (194).

Recordemos que la recreación de Cieza de la travesía de Alvarado recurre también a las figuras del cuerpo que descansa en la peña y al jinete que se congela con la rienda en la mano. Se trata de los mismos motivos que Cieza va a utilizar al dar cuenta del cruce cordillerano por Almagro:

Las noches que durmieron en los puertos fueron tan travajosas, temerosas y espantables que les pareçía estar todos en los ynfiernos [...] muriéronse treynta cavallos y muchos yndios e yndias y negros arrimados a las rocas, boqueando se les salía el ánima; sin toda esta desventura avía tan grande anbre que muchos de los yndios bivos comían a los muertos; los cavallos, que de elados avían quedado, de buena gana los comieron los españoles, más, si paravan a los desollar, se vieran como ellos. Y así, quentan que un negro que yendo con un cavallo de diestro reparó a unas bozes que oyó, y que luego quedó elado él y el cavallo (331).

${ }^{5}$ En circunstancias que el regreso fue por el camino de la costa, atravesando el Despoblado de Atacama. 
Respecto de este pasaje, me interesa destacar, en particular, la asociación entre el tormento en la cordillera y el infierno, como lugar de superiores tormentos. Esta contigüidad no podía sino evocar la noción de perpetuidad, la permanencia en el tiempo de los trabajos padecidos: el infierno donde los cuerpos arden por siempre en el fuego sin consumirse, lo mismo que se conservan por siempre en el frío de la cordillera. Esta figura de la permanencia del cuerpo ya desprovisto de alma se refuerza con las sucesivas reiteraciones a la presencia de la muerte en la forma de un asombroso rictus de vida.

\section{ECOS DE FRÍO}

A partir de las resonancias entre los relatos presentados, nos parece importante preguntarse qué pasa cuando un conjunto de acontecimientos adquiere suficiente consistencia simbólica como para ser contado sucesivas veces. Aun cuando la tradición escrita sea fundamental para entender este proceso, debe recalcarse que las fuentes de los textos no siempre residen en esa práctica sino también en otra, la oral, que a trechos parece discurrir de manera paralela ${ }^{6}$. La coincidencia en el tratamiento de acontecimientos en los textos coloniales desde la pregunta por la precedencia, la copia, la cita y las relaciones efectivas entre sujetos y obras (quién conoció a quién, quién leyó a quién, etc.) ha permitido identificar un primer nivel de interacción entre los escritos. Desde este ángulo, las convergencias en los textos de Zárate y López de Gómara al dar cuenta de diversos acontecimientos han sido ampliamente comentadas por la historiografía especializada, lo mismo que la utilización del manuscrito de Oviedo por parte de Gómara o, algunas décadas más tarde, de la Crónica de Cieza por Antonio de Herrera. Es así como podemos reconocer que estos fragmentos forman parte, efectivamente, de "una vasta red de textos, de una trama siempre mayor de palabras, enunciados y discursos $[\ldots]$ una parte importante de esas palabras, de sus 'decires', remiten precisamente a esos otros textos" (Martínez, Textos 272).

A partir de estas indicaciones, nuestra lectura sugiere atender a las relaciones de no exclusión entre escritura y oralidad. Fundamental resulta, en este sentido, la indicación de David Olson, en cuanto a que el discurso oral precede y rodea la preparación, interpretación y comprensión del discurso

${ }^{6}$ Esta pregunta constituye una paráfrasis de las palabras de Cornejo Polar (Escribir 26). 
escrito (Olson 8$)^{7}$. Nos parece que ésta puede resultar una entrada fructífera para pensar la reiteración de enunciados y motivos insertos en relatos que divergen en su tratamiento de los acontecimientos. Así, podemos entender cómo un mismo repertorio de figuras e imágenes se utiliza para dar cuenta de diferentes expediciones: la de Alvarado a Quito, la de Almagro a Chile. En segundo lugar, pues estas reiteraciones ocurren pese a que se narran diferentes versiones de una misma expedición: como la ficcionalización del retorno de Almagro por la cordillera, atribuyéndole a su hueste el encuentro con despojos helados que en otros relatos corresponde a lo ocurrido a los refuerzos que venían tras Almagro, al mando de Rodrigo de Orgóñez y Juan de Herrada.

Es aquí donde la sugerencia de Cornejo Polar de atender a la consistencia y eficacia simbólica de las imágenes adquiere todo su interés. Sin negar la función legitimadora de la palabra escrita en el proceso colonizador (Mignolo, Cuestión 97-112), en particular, como una de las modalidades mediante las cuales se fija la jerarquía entre conquistadores y conquistados, queremos llamar la atención sobre la circulación oral de noticias entre grupos de conquistadores que también debió contribuir a la fijación de enunciados, episodios y sus significados en la naciente sociedad colonial del Perú.

Varias décadas después de que fueran escritos los textos que hemos presentado, el jesuita Joseph de Acosta vuelve a consignar en su Historia natural y moral de las Indias fragmentos de los relatos a los que hemos aludido, al presentar una caracterización del espacio geográfico cordillerano:

En tiempos pasados caminaban los españoles del Perú al reino de Chile por la sierra, ahora se va de ordinario por mar, y algunas veces, por la costa, que, aunque es trabajoso y molestísimo camino, no tiene el peligro que el otro camino de la sierra, en el cual hay unas llanadas donde, al pasar, perecieron muchos hombres y otros escaparon con gran ventura, pero algunos de ellos mancos o lisiados. De allí un airecillo no recio, y penetra de suerte que caen muertos cuasi sin sentirlo, o se les caen cortados de los pies y manos dedos, que es cosa que parece fabulosa y no lo es, sino verdadera historia (106).

Para afirmar la veracidad de lo relatado, Acosta remite a los testigos de vista: 16-40).

${ }^{7}$ Para el caso colonial americano, estos temas han sido tratados por Martínez (Pública 
Yo conocí y traté mucho al general Jerónimo Costilla, antiguo poblador del Cuzco, al cual le faltaban tres o cuatro dedos de los pies que, pasando por aquel despoblado a Chile, se le cayeron, porque, penetrados de aquel airecillo [...]

Y aún añadía [Jerónimo Costilla] otra cosa extraña, que hallaron vivo un muchacho, y, preguntado cómo había vivido, dijo que escondiéndose en no sé qué chocilla, de donde salía a cortar con un cuchillejo de la carne de un rocín muerto, y así se había sustentado largo tiempo; y que no sé cuántos compañeros que se mantenían de aquella suerte, ya se habían acabado todos, cayéndose un día uno y otro día otro amortecidos, y que él no quería ya sino acabar allí como los demás, porque no sentía en sí disposición para ir a parte ninguna, ni gustar de nada. La misma relación oí a otros, y, entre ellos, a uno que era de la Compañía y siendo seglar había pasado por allí [...]. Me refirió un religioso grave, dominico, y prelado de su Orden, que lo había él visto, pasando por aquellos despoblados; y aún me contó que, siéndole forzoso hacer noche allí para ampararse del vientecillo, que digo que corre en aquel paraje tan mortal, no hallando otra cosa a manos, juntó cantidad de aquellos cuerpos muertos que había al derredor y hizo de ellos una como paredilla por cabecera de su cama; y así durmió, dándole la vida los muertos (106-107) ${ }^{8}$.

En estos fragmentos se alude a lo que refieren diferentes testigos de los hechos. Si bien, en un primer nivel, reconocemos allí un dispositivo retórico de validación epistémica, nos parece que igualmente se apunta a la efectiva circulación oral de historias en el entorno de los conquistadores del Perú. Acosta remite de manera explícita al espacio de la conversación cuando señala que "oyó decir a otros", que tal "añadía", "le refirió" y "le contó". Interlocutores identificados -y otros anónimos-se inscriben en la trama escrita del jesuita al fijar en su escrito el pasado reciente mediante expresiones que evocan los actos del habla9.

Lo mismo puede decirse de las narraciones de las expediciones de Alvarado y Almagro, que hemos referido. Aunque por la mayor parte éstas

${ }^{8}$ Los destacados con cursiva son nuestros.

${ }^{9}$ Olson identifica este vocabulario como un metalenguaje propio de las tradiciones orales y escritas para distinguir la palabra directa de la palabra referida, aunque cumplen, en estos contextos, funciones más o menos determinantes en la medida en que el discurso escrito no tiene la misma capacidad ilocutoria que el oral $(97,108)$. 
se construyen en el modo indicativo/descriptivo propio de la prescriptiva historiográfica ("hay"...", "hallaron...", etc.), hay asimismo indicaciones que remiten al espacio de la oralidad: "según dicen” (López de Gómara 194); "quentan que..." (Cieza 331).

Siguiendo en ello a Lienhard, creemos que ciertas incoherencias del discurso publicado -en este caso las coincidencias y las diferencias inesperadaspermiten penetrar en el pensamiento que auspició la producción del testimonio en su forma primitiva, oral (69). Aunque la afirmación citada de este autor refiere a la presencia de testimonios indígenas "cautivos" en la escritura hispana, nos parece fructífera para pensar el momento de la fijación de figuras e imágenes asociadas al relato de la conquista. Vemos que estas imágenes desempeñan un función nemotécnica o de anclaje ${ }^{10}$, que apunta a una manera de proceder diferente del relato escrito; imágenes que se superponen y, en ese sentido, gozan de cierta autonomía respecto de la secuencia misma de los acontecimientos narrados.

Con estos antecedentes, parece pertinente preguntarse qué otras tramas favorecen la superposición entre la experiencia cordillerana de Alvarado y Almagro, más allá de las confluencias contextuales a las que ya he aludido. Me parece que la inscripción de estos dos episodios en la secuencia mayor de la expansión hispana concebida como una narración unitaria puede resultar provechosa para pensar el problema, en la medida en que Quito y Chile se configuran en la cultura de la conquista de la década de 1530, que nos ocupa, como los límites septentrional y meridional del espacio del Perú a conquistar.

¿A qué Perú nos referimos? Al iniciarse el siglo siguiente, Antonio de Herrera, a la sazón Cronista de Indias, nos recuerda en su Descripción de las Indias Occidentales (1601) -la introducción al primer volumen de sus Décadas - que el Perú "se ha ydo extendiendo más de lo que fue al principio" (46), dado que en los primeros lustros del avance hispano por la América del sur el topónimo se vinculaba directamente con el territorio del Tawantinsuyu.

En este contexto, quisiera llamar la atención sobre la presencia del enunciado "Quito y Chile" que he podido identificar en algunos escritos coloniales del periodo para referir a los límites del Perú. No se trata de una

${ }^{10}$ Barthes (1964) introduce este término para referir al efecto del texto que limita los alcances connotativos de la imagen. Por el contrario, en este caso nos permite sugerir cómo una imagen fija el significado de un relato. 
indagación exhaustiva, sino de la indicación de una recurrencia que quisiera poder perfilar con más claridad en el futuro.

En primer lugar, traigo a colación la Historia de López de Gómara, que ya he presentado. Una vez que Gómara da cuenta de la consolidación del poder imperial por obra del llamado pacificador Pedro de la Gasca, introduce un capítulo denominado La calidad y temple del Perú, que se inicia con la siguiente afirmación: "Llaman Perú todas aquellas tierras que hay del mismo río al Chili, y que nombrado habemos muchas veces en su conquista y guerras civiles, como son Quito, Cuzco, Charcas, Puerto-Viejo, Túmbez, Arequipa, Lima y Chili" (278). Este listado de topónimos que permiten definir "lo que llaman Perú" se inicia con Quito, para cerrarse con Chili, desplegando entre estos dos límites una secuencia de topónimos que no obedece a una lógica única que yo pueda identificar.

El siguiente texto que presento es una obra compilatoria realizada entre 1571 y 1574 por el cosmógrafo y cronista mayor de las Indias, Juan López de Velasco, titulada Geografía y descripción universal de las Indias. Redactada en la metrópolis a partir de los papeles que afluían al Consejo, según declaración expresa del autor, la Geografía ha sido recientemente releída desde la intertextualidad impuesta por su condición de "colcha de retazos"11. En la introducción general a la descripción de las Indias del Mediodía, López de Velasco consigna: "Hubo en estas partes del mediodía un imperio, que fue el de los Ingas, como en las Indias del Norte el mexicano [...] y así, en todo lo que alcanzó, que fue desde Quito hasta Chile, los señores dél reinaron muy absoluta y tiránicamente y no sin alguna grandeza y magestad" (338-339). En la declaración de López de Velasco, el enunciado "desde Quito hasta Chile" marca los límites septentrional y meridional, ya no del Perú en general, sino de lo que fuera, muy particularmente, el imperio de las Ingas.

Algunos años más tarde, y en respuesta al envío de un cuestionario a territorios americanos por parte del propio López de Velasco, se redactaron documentos que la historiografía conoce como las Relaciones Geográficas de Indias. Entre ellas, la "Relación de la Villa Rica de Oropesa y Minas de Huancavelica", elaborada en 1586 por el corregidor de dicha ciudad, Rodrigo de Cantos de Andrade, señala lo siguiente: "Todo este reino del Pirú de Quito hasta el río de Arauco en Chile era sujeto y obedecían a los Ingas" (Jiménez

${ }^{11}$ La expresión es de Carmen Millán de Benavides (2001). 
de la Espada, tomo I 307). Aquí se reitera la asociación entre Perú, los Ingas, y "Quito hasta Chile".

Por último, quisiera traer a colación la discusión que hemos sugerido con José Luis Martínez respecto de las rupturas epistémicas en la conceptualización del espacio del Perú que acompañan la imposición del programa imperial hispano. Entre los documentos que allí se analizan, destaca la probanza presentada ante las autoridades coloniales por varios miembros de la élite cuzqueña, destinada a certificar su condición de descendientes de Thupaq Inka Yupanqui. El escrito contiene varios documentos, uno de los cuales lleva por título "Memoria de las provincias" y se inicia con el siguiente texto: "memoria de las prouinçias que conquisto topa ynga yupangui padre de guayna capac ynga con sus hermanos amaro topa ynga y topa yupangui en la prouinçia de chinchaysuyo y collasuyo andesuyo y condesuyo hasta quito chile" (cit. Martínez y Vega 64). El documento, como bien lo destacó el investigador John Rowe (cit.), nombra estas provincias siguiendo un ordenamiento que impone la pertenencia a los cuatro grandes suyus del imperio. Sin embargo, el encabezado del documento que citamos contiene el enunciado "hasta Quito Chile", fijando unos bordes, en el sentido norte sur, que apelan a los límites septentrionales y meridionales de la expansión cuzqueña. Tal como se señala en el artículo al que refiero, "no creemos arriesgado postular que, en esta ruptura descriptiva bien pudo hallarse la mano de un escribano español, interesado en obtener una mejor comprensión europea de los límites del Señorío de los inkas y, sobre todo, portadora de una conceptualización del espacio diversa, estructurada epistémicamente en torno al eje norte-sur" (ibíd 65), a diferencia de la división cuatripartita centrada en el Cuzco con la que se articuló el Tawantinsuyu.

\section{A MODO DE CIERRE}

La conceptualización hispana del espacio a la cual se alude permite entender la superposición entre los relatos de Quito y Chile que he presentado en este artículo. Si la invención del espacio colonial operó, en un momento dado, asociando estos dos topónimos como bordes o límites del territorio inka que se estaba reconociendo y conquistando por esos mismos años, esta misma asociación pudo resonar al momento de fijar los relatos de las expediciones de Alvarado y Almagro. A modo de espejos distantes, Quito y Chile, y los fracasos asociados a sus cumbres frías y nevadas, marcaron las narraciones 
de la conquista, relatadas y repetidas por una generación de conquistadores, y como tal fueron recogidas por las historias y crónicas escritas algunos años después. Siguiendo la indicación de Edmundo O'Gorman en cuanto a la impertinencia de leer los documentos que nos legó la tradición colonial como "cantera de datos", esta propuesta apunta a pensar los contextos específicos en que se configuraron imágenes e imaginarios. Si hoy el binomio Quito Chile carece de sentido, resulta relevante poner atención al breve periodo en que éste fundó la producción de relatos sobre el espacio conquistado, articulando en la conversación lo que los escritos vendrían a sancionar después.

\section{FUENTES IMPRESAS}

Acosta, José de. Historia natural y moral de las Indias, en que se trata de las cosas notables del cielo, elementos, metales, plantas y animales dellas, y los ritos y ceremonias, leyes y gobierno de los indios. Ed. Edmundo O'Gorman. México: Fondo de Cultura Económica, 1962.

Cieza de León, Pedro. Crónica del Perú. Primera, Segunda, Tercera y Cuarta Partes. Ed. Franklin Pease y Miguel Maticorena. Lima: Pontificia Universidad Católica del Perú, 1996-1997.

Diccionario de Autoridades. Diccionario de la lengua castellana, en que se explica el verdadero sentido de las voces, su naturaleza y calidad, con las phrases o modos de hablar, los proverbios o refranes y otras cosas convenientes al uso de la lengua [...] compuesto por la Real Academia Española. Madrid, Imprenta de Francisco del Hierro, 1726-1739, 6 vols., en http://buscon.rae.es/ntlle/SrvltGUILoginNtlle (30/05/2008).

Fernández de Oviedo, Gonzalo. Historia general y natural de las Indias, Islas y Tierra Firme del mar Océano, por el capitán ... Ed. José Amador de los Ríos. Madrid: Imprenta de la Real Academia de la Historia, 1851-1855, 4 tomos.

Herrera, Antonio. Historia general de los hechos de los castellanos en las Islas i tierra firme del Mar Océano escrita por ... Madrid: Imprenta Real, 1601.

Jiménez de la Espada, Marcos. Relaciones Geográficas de Indias, Perú. Madrid: Biblioteca de Autores Españoles, Atlas, 1965. 3 tomos.

López de Gómara, Francisco. Historia General de las Indias y vida de Hernán Cortés. Ed. Jorge Gurría Lacroix. Caracas: Biblioteca Ayacucho, 1978.

López de Velasco, Juan. Geografía y descripción universal recopilada por ..., Ed. Justo Zaragoza. Madrid: Establecimiento Tipográfico de Fortanet, 1894.

Palencia, Alfonso de. Universal vocabulario en latín y en romance. Alicante: Biblioteca Virtual Miguel de Cervantes/ Madrid: Biblioteca Nacional, 2005. Reproducción digital de la edición de Sevilla, 1490, II tomos, en: http://www.cervantesvirtual.com/FichaObra. html?Ref=14654 (30/05/2008). 
Vives, J. L., "Narración. De la narración histórica". Antología de textos retóricos españoles del siglo XVI. Ed. Elena Artaza. Bilbao: Universidad de Deusto, 1997. 88-96.

Zárate, Agustín de. Historia del descubrimiento y conquista del Perú. Lima: Pontificia Universidad Católica del Perú, 1995.

\section{BIBLIOGRAFÍA}

Barthes, Roland. "La rhétorique de l'image. Communication 4 (1964): 40-51.

Cornejo Polar, Antonio. 'La 'Invención' de las naciones hispanoamericanas. Reflexiones a partir de una relación textual entre el Inca y Palma”. Discursos sobre la 'invención' de América. Ed. Iris Zavala. Ámsterdam/Atlanta: Rodopi, 1992. 139-156.

Escribir en el aire. Ensayos sobre la heterogeneidad socio-cultural en las literaturas andinas. Lima/Berkeley: Latinoamericana Editores/CELAC, 2003.

Curry, Michael R. "Discursive Displacement and the Seminal Ambiguity of Space and Place". Eds. Leah Lievrouw y Sonia Livingstone The Handbook of New Media: Social Shaping and Consequences of ICT. Londres: Sage Publications, 2002. 502-517.

De Ramón, Armando. Descubrimiento de Chile y compañeros de Almagro. Santiago: Universidad Católica de Chile, 1953.

Esteve Barba, Francisco. Cultura virreinal. Barcelona: Salvat Editores, 1965.

Gómez Pérez, Carmen y Juan Marchena. "Las sociedades indígenas y los conquistadores. Apus y supays". Historia de América Andina. Vol. II Formación y apogeo del sistema colonial (siglos XVI-XVII). Ed. Manuel Burga. Quito: Universidad Andina Simón Bolívar, 2000.

Hartog, François. El espejo de Heródoto. México: Fondo de Cultura Económica, 2003.

Invernizzi, Lucía. "Estructura de la Historia de Góngora Marmolejo". Alonso de Góngora Marmolejo. Historia de todas las cosas que han acaecido en el Reino de Chile y de los que lo han gobernado. Santiago: Ediciones de la Universidad de Chile, 1990. 21-67.

Lienhard, Martín. "El cautiverio colonial del discurso indígenas: los testimonios". Discursos sobre la 'invención'de América. Ed. Iris Zavala. Ámsterdam/Atlanta: Rodopi, 1992. 55-71.

Martínez, José Luis, “Textos y palabras. Cuatro documentos del siglo XVI”. Espacio, etnías, frontera. Atenuaciones políticas en el sur del Tawantinsuyu, siglos XV-XVIII. Ed. Ana María Presta. Sucre: Ediciones ASUR n 4, 1995. 251-283.

"Pública voz y fama: una aproximación a los espacios discursivos coloniales en el siglo XVI”. Revista Chilena de Humanidades 16 (1995): 16-40.

Martínez, José Luis y Alejandra Vega. "Narraciones imperiales contrapuestas: los suyus cuzqueños y el eje norte-sur español en la construcción de la espacialidad del Perú colonial". Los Andes y las poblaciones altoandinas en la agenda de la regionalización y la descentralización. Ed. Hilda Araujo Camacho. Lima: Concytec, 2008. 63-66.

Mignolo, Walter. "Cartas, crónicas y relaciones del descubrimiento y la conquista". Historia de la literatura hispanoamericana. Tomo I. Época colonial. Coord. Luis Iñigo Madrigal. Madrid: Ediciones Cátedra, 1982. 57-114. 
"La cuestión de la letra en la legitimación de la conquista". En Kohut, Karl, De conquistadores y conquistados. Realidad, justificación, representación. Frankfurt: Americana Eystettensia, Zentralinstitut für Lateinamerika-Studien der Katholischen Universität Eichstätt/ Vervuert Verlag, 1992. 97-112.

Millán de Benavides, Carmen. Epítome de la Conquista del Nuevo Reino de Granada: la cosmografía española del siglo XVI y el conocimiento por cuestionario. Bogotá: Pontificia Universidad Javeriana/ Instituto de Estudios Sociales y Culturales 'Pensar', 2001.

O'Gorman, Edmundo. Cuatro historiadores de Indias. México: Alianza Editorial Mexicana, 1989.

Olson, David. The word on paper. The conceptual and cognitive implications of writing and reading. Cambridge: Cambridge University Press, 1994.

Pastor, Beatriz. Discurso narrativo de la conquista de América. La Habana: Edición Casa de las Américas, 1983.

Pease, Franklin. "Introducción”. En Agustín Zárate, Historia del descubrimiento y conquista del Perú. Lima: Pontificia Universidad Católica del Perú, 1995.

Las crónicas y los Andes. México: Fondo de Cultura Económica, 1995.

Stoll, Eva. "Géneros en la historiografía indiana: modelos y transformaciones". E. Stoll, W. Oesterreicher y A. Wesch (eds.). Competencia escrita, tradiciones discursivas y variedades lingüisticas: aspectos del español europeo y americano en los siglos XVI y XVII. Tubingen: Gunter Narr Verlag Tubingen, 1998. 143-168.

Vega, Alejandra. Descripción geográfica e identidad territorial: representaciones hispanas de la cordillera de los Andes del reino de Chile en el siglo XVI. Tesis doctoral. Pontificia Universidad Católica de Chile, 2005. 